\title{
Factors Affecting Job Announcement Competitiveness on Job Listing Websites
}

\section{- Zoltan Rozsa, Veronika Machova}

\begin{abstract}
Recruitment as a Human Resource Management function is seen as the factor influencing the development of a competitive advantage. Merely a moment in the online environment can determine whether a potential job candidate responds to a job offer, and thus factors influencing the candidate's attention also influence the employer's competitiveness. The paper aims to determine factors that affect job pursuit intentions (JPI) in the job listing websites environment based on the evaluation of a particular job offer that has attracted the respondent. Data was collected from a randomly selected sample of 412 Czech (CR) and Slovak Republic (SR) university students (effective response rate 29.11 percent). Multiple linear regression was used to determine independent variables to help explain the response. Two models were constructed: the first model contained all suspected variables (explaining the variance of 34.59 percent); the second model also contained their second-degree combinations (explaining the variance of 40.23 percent). The results showed that informativeness about salary and benefits (ISB), employer attractiveness (EA), informativeness about employee responsibilities (IER), as well as informativeness about work-life balance (IWLB) significantly affected job pursuit intentions (JPI) in both models. The second model revealed that the attractiveness of content (CA) also contributes to explaining variance by this factor's affecting of the attractiveness of the employer (EA). The study extends the research into job pursuit intention into the online environment, with empirical validation of the models showing the mechanisms and conditions through which the selected variables affect job pursuit intention. The conclusion also offers suggestions for future work that can identify and more deeply describe factors which attract job candidates.
\end{abstract}

Keywords: job pursuit intentions, multiple linear regression, job candidates, competitive advantages, online environment

JEL Classification: C30, M51

Received: February, 2020

1st Revision: August, 2020

Accepted: September, 2020

\section{INTRODUCTION}

Today the labor market can be characterized as a candidate's market with a strong demand for employees. As the market is becoming more competitive, identifying suitable employees from the pool of candidates is an increasingly demanding task (Sander \& Teh, 2019; Malega et al., 
2019). Organizations, therefore, must develop competitive strategies and tactics to attract only the right employees (Beenen \& Pichler, 2014), and this should be accomplished during the early phase of recruitment. Consequently, in a highly competitive marketplace, recruitment has emerged as a key indicator of organizational competitiveness. Furthermore, learning how to attract the best applicants has become critical for many organizations (Chapman et al., 2005; de Cooman \& Pepermans, 2012).

This situation has not changed with the impact of the coronavirus - COVID 19. It can be assumed that these recruitment trends are long-term and result from demographic developments, while the coronavirus situation is temporary. In addition, recruitment can be expected to be gradually transferred to a greater degree to the online environment. These developments are also borne out by the reality that the next generation of employees will be exclusively digital natives.

Barber (1998) has defined recruitment as a system of methods and actions with the fundamental goal of recognizing and inviting possible employees. Specifically, with regard to external recruitment, Breaugh (2008) describes it as planned activities aimed at creating and focusing attention to the jobs on offer. These activities draw the attention of potential jobseekers to the existence of new posts as well as affect their interest in applying for employment along with their willingness to accept a job offer. At the same time, an organization should be able to create a comprehensible strategy at least to address the question of which information to communicate to new position candidates. The initial or early recruitment stage in particular is crucial to insure that the subsequent steps of the recruitment process proceed successfully. If applicants are not willing to engage with a company upon first encountering it, they will not engage with it at all (Arijs et al., 2018; Stachová et al., 2019). The situation is becoming even more significant in small and medium-sized enterprises (SMEs), as they contribute considerably to the creation of new jobs (Dvorsky et al. 2020; Koisova et al., 2017) and are also considered to be one of the primary sources of economic and employment growth (Mura, 2019; Gavurova et al. 2017).

Although recruiting through a company or jobs listing web site shares many similar characteristics with more conventional recruitment techniques, there are also some differences. For instance, websites allow communicating practically unlimited information about the company in various forms (e. g. plain text, images, audios, videos, animations, links) (Allen et al., 2007). Job seekers are in this way led to seek more extensive information about an employer (Ghielen et al., 2018) simply because it is so easy and convenient to do so in the online environment. Nevertheless, this may not be the best strategy for employers, mainly because of the glut of information on the internet (as well as information overload in the environment general) which easily distracts candidates and limits their attention. Therefore, organizations need to focus on publishing the right information at the right time to the right candidates.

Another challenge is that job listing websites provide potential job seekers with the opportunity to easily compare several job offers. They can then choose one that best matches their qualifications and needs. (Braddy et al., 2006). This possibility of comparison again further highlights the need for companies to prepare attractive offers. 
Despite the widespread use of the job listing websites for recruitment purposes, little is known about how job seekers process and evaluate the information presented (Gregorka et al., 2020; Hinojosa et al., 2015; Priyadarshini et al., 2019; Shahbaz et al., 2019). Exactly which information is best to stimulate a candidate's job pursuit intentions (JPI) must be determined. In order to address the mentioned research gaps in the existing literature, the study aims to determine factors that affect job pursuit intentions (JPI) in the job listing websites environment.

The paper has the following structure. Firstly, it discusses the literature on job pursuit intention. This is followed by the methodology section, which explains the research context as well as the methods of data collection and analysis. In the section which follows a discussion of the results will be presented as well as the implications for HRM literature and practice. Finally, the paper concludes with suggestions for future research directions.

\section{THEORETICAL BACKGROUND}

\subsection{Job pursuit intentions (JPI)}

Job pursuit intentions (JPI) can be defined as the willful act of taking active steps to gain indepth knowledge about the organization, establish closer contact with it, and to arrange a job interview (Aiman Smith et al., 2001), or as Arijs et al. (2018), the process of starting to consider a particular organization as the right place to seek and secure employment. Job pursuit intentions (JPI) in the early recruitment stage refer to the range in which persons looking for a job attempt to find out career-useful information about the potential employer (Beenen \& Pichler, 2014), or the applicant at least has the desire to be included in the organization's list of potential job candidates (Chapman et al., 2005). Moreover, persons who would like to work for an organization will also try to actively acquire more profound knowledge about the organization to better succeed in selection procedures (Hinojosa et al., 2015).

According to Highhouse et al. (2003), the assessment of affective responses to organizational recruitment messages is based on the assumption that these responses can be generalized to actual organization choice. In contrast with organization attractiveness as such, intentions move beyond passivity, and they thus will likely be limited to a selection of a smaller subset of potential employers.

Published researches in the recruitment domain have revealed several independent variables that have been used to assess applicant reactions to the employment opportunity in the online environment. The findings can be in principle split into two groups. The first group of scholars declares that job seeker intention cannot be arbitrarily increased or forced by immediate recruitment campaigns; intention depends mostly on employer attractiveness (EA). The second group considers the more specific the information provided to the applicant during recruitment as resulting in higher job pursuit intentions (JPI). In the second group, we can also include works studying the impact of wording or visual attractiveness on job pursuit intentions (JPI), e.g., humorous text; a personal, friendly and sociable way of communication; as well as the use of multimodal features such as text, graphics, video, and sound. 


\subsection{Employer attractiveness (EA)}

The current debates about employer attractiveness (EA) reveal that it can be defined based on the benefits a potential employee expects to receive when working for a particular organization (Berthon et al., 2005). This factor can be operationalized as an attitude or influence on the perception of the organization "as a desirable entity with which to initiate some relationship" (Aiman Smith et al., 2001). Employer attractiveness (EA) thus refers to the extent of how potential applicants perceive organizations as the right places to work (Jiang et al., 2011; Rynes et al., 1991). In the context of this study, employer attractiveness (EA) can be defined as benefits that are related to the firm's reputation or result from belongingness to a specific group of companies (e.g., sector, familiarity with an organization, reputation, organizational culture).

Peiffer et al. (2018) confirmed assumptions relating to the relationship between the sector and the organization's distorted images and job pursuit intentions (JPI). According to them, job pursuit intentions (JPI) for a specific organization can be predicted by the perception of the organization's and sector's warmth and competence. Specifically, the sector's warmth and competence are essential in the for-profit sector, while the organization's and sector's warmth and competence affect job pursuit intentions (JPI) in the non-profit sector. Arijs et al. (2018) indicate that also the family business employer brand's instrumental and symbolic components can affect the intent to pursue a job in a family firm, too.

As websites are fast, becoming an essential part of recruiting, Allen et al. (2007) tested the critical components of traditional recruitment theory, such as the image of organizations, in the online environment. Contrary to the first group of scholars, they suggest that the impact of an organization's image in the online environment on the perceived attractiveness of an organization can be overcome by exposing it to the workplace's reality.

Wang (2013) reveals that the beliefs or opinions generally held about an organization are positively related to job pursuit intentions (JPI) and willingness to recommend the organization. He also argues that job seekers' intentions can be improved in the long term by the social actions of their target organization. Kumari \& Saini (2018) state that the symbolic feature of employer attractiveness (familiarity of the firm), which is known to potential applicants very early in the recruitment process, had a significant influence on how positively the participants rated the job offer. Baum \& Überschaer (2018) confirmed that the use of recognized awards in the recruiting process improves applicants' job pursuit intentions.

Regarding the influence of organizational culture on job pursuit intentions (JPI), the results indicate the differences between men and women considering the choice of which organization they would like to work for. Men are more likely to choose an organization with a competitive organizational culture, while women instead prefer a supportive one (Catanzaro et al., 2010). In terms of externally presented values as a part of the organizational culture, several researchers have conducted research related to religious values or CSR. For example, the presentation of religious values in an organization's media communications led to lower job pursuit intentions than openly professed non-religious values (Neubert \& Wood, 2019). Tsai et al. (2014) confirmed that declaring an effort to reach economic, legal, ethical, or philanthropic citizenship attracts potential people looking for a job. In another study, they also confirmed that organizations' perceived corporate credibility, positive publicity, and corporate social responsibility are positively 
linked to job pursuit intentions (JPI) and word-of-mouth. These connections are mediated by organizations' attractiveness and job seekers' career expectations (Tsai et al., 2015). According to Belinda et al. (2018), online CSR information supports human resources professionals' ideas about organizations' success and provides a high-level, strategic view for attracting highly-skilled and valuable employees. Accordingly, it can be hypothesized (H1) that after viewing a job announcement in the job listing websites environment, the higher employer attractiveness (EA) will result in higher job pursuit intentions (JPI).

\subsection{The content informativeness}

According to Maurer \& Liu (2007), during the early recruitment phase, the amount and kind of information content (message) presented during the early recruitment stage is the most elementary design components that have to be reflected, which in practice means that mainly "richness" of available information needs to be considered, and, therefore, it is a decision as to whether the published information should be detailed or just the cursory.

Al Marri (2015) carried out an empirical study on questions about whether recruitments websites have a positive effect on job candidate fascination. In line with previous findings, he takes the view that high data's recruitment sources have a huge constructive effect on the potential candidates. In this context, the following factors influencing the choice of employer are most frequently mentioned: H21 employees' responsibilities (IER), H22 salary and benefits (ISB), H23 training opportunities (ITO), H24 security of employment (ISE), H25 working atmosphere (IWA), H26 work-life balance (IWLB), and H27 career opportunities (ICO) (Chitu et al., 2014; Word et al., 2015).

Also, Verwaeren et al. (2017), in their work "The Specificity of Compensation and Benefits Information in Job Advertisements," have found out that more specific compensation and benefits information (H22) results in higher job pursuit intentions, especially in situations where competitive packages are provided. Moreover, it seems that information about future remuneration and benefits is used by job applicants to form perceptions not only about remuneration and benefits appropriateness but also about broader organizational attributes.

In this context, it should be also noted that the research results suggest that Millennium workers value work-life balance more than previous generations (Yang et al., 2020).

Therefore, it can be assumed (H2) that content informativeness will connect to the job pursuit intentions (JPI), in the sense that announcements with detailed information will result in higher job pursuit intentions (JPI).

\subsection{The content attractiveness}

The last group of published works deals with the impact of the job announcement mood or degree to which the employer's website provides rich information directly perceived by the human senses (Maurer \& Liu, 2007) job on pursuit intentions (JPI). For example, humor content has no impact on intentions to apply for the job. Yet, humor content intensifies willingness to share job ads, which is a valuable marketing reaction with increased importance, specifically in the social media environment (Oikarinen \& Söderlund, 2016). 
Potential applicants create a mental picture of what the organization is as an employer based on how organizations communicate. Attractive content is often willingly shared and disseminated in the online environment. Hence, a more personal, friendly, and sociable way of communication leads to an overall warmer perception of organizations. Further, organizations that provide more compelling information about the job offered are perceived as more competent (Carpentier et al., 2019). Therefore, it can be proposed (H3) that the content attractiveness of the online announcement (CA) affects job pursuit intentions (JPI).

\section{RESEARCH OBJECTIVE, METHODOLOGY, AND DATA}

\subsection{The aim, hypotheses, and variables}

This study aims to determine the factors that affect job pursuit intentions (JPI) in the job listing websites environment.

The hypotheses were formulated as follows:

H1: The employer attractiveness (EA) significantly contributes to job pursuit intentions (JPI).

H2: Announcements concerning the detailed information (about H21 employees' responsibilities (IER), H22 salary and benefits (ISB), H23 training opportunities (ITO), H24 security of employment (ISE), H25 working atmosphere (IWA), H26 work-life balance (IWLB), H27 career opportunities (ICO)) significantly contribute to job pursuit intentions (JPI).

H3: The content attractiveness of the online announcement (CA)) significantly contributes to job pursuit intentions (JPI)

\section{Measuring the employer attractiveness (EA) - independent variable}

To measure the employer attractiveness (EA), Kissel \& Buttgen (2015) scale was used with components as follows: (1) This employer offers attractive jobs. (2) This employer differentiates itself positively from others. (3) This is an employer I can identify with very well. (4) I like this employer. (5) I feel attached to this employer. (6) This employer meets my expectations. (7) I feel confidence in this employer. (8) I believe this employer would make an effort to satisfy me as an employee. (9) I believe this employer cares much about fulfilling the needs of its employees (Kissel \& Buttgen, 2015). The results showed high internal reliability of the scale (Cronbach alpha $=0.87)$.

\section{Measuring the informativeness of online job announcement - independent variable}

The informativeness of online job announcement was measured according to the variables such as employees' responsibilities (IER), salary and benefits (ISB), training opportunities (ITO), the security of employment (ISE), working atmosphere (IWA), work-life balance (IWLB), career opportunities (ICO).

Measuring the content attractiveness of online job announcement - independent variable

The content attractiveness of the online announcement (CA) was evaluated as the degree to which selected announcement captured respondents' interest. 


\section{Measuring the job pursuit intentions (JPI) - dependent variable}

Although the definition of the job pursuit intentions (JPI) is clear, there is no consensus on how to measure its components between the scholars. In the literature, we can mainly identify measurement approaches based on the works of Aiman Smith et al., 2001; Arijs et al., 2018; Catanzaro et al., 2010; Highhouse et al., 2003; Baum \& Überschaer, 2018; Hinojosa et al., 2015; Neubert \& Wood, 2019; Peiffer et al., 2018; Verwaeren et al., 2017; Kumari \& Saini, 2018; Thompson et al., 2008; Tsai et al., 2014; Tsai et al., 2015; Macan et al., 1994; Madera, 2012. It is also possible to find an individual approach to measurements (Allen et al., 2007; Beenen \& Pichler, 2014).

For the reason of early recruitment stages, job pursuit intention (JPI) should reflect an active and forward-looking applicant's approach to dealing with the company in the future. For this reason, two items were sorted by Aiman Smith et al. (2001) and one from Highhouse et al. (2003) was adopted. On that basis, we operationalized job pursuit intentions (JPI) with the following items: (1) I would make this company one of my first choices as an employer. (2) I would request more information about this company. (3) I would actively pursue obtaining a position with this company. The results showed high internal reliability of the scale (Cronbach alpha $=0.86)$.

\subsection{Data collection process}

This study used a quantitative approach through survey research. The data was collected from a sample of the Czech (CR) and Slovak Republic (SR) university students.

Firstly, the faculties with the Economics and Management field of study list was created based on the information available in the register of faculties and their study programs (CR: https:// regvssp.msmt.cz/registrvssp/; SR: https://www.portalvs.sk/sk/). The total number of students in the Economics and Management field of study was approximately 67,000 in 2019. Secondly, the faculties offering Human Resource Management subject during the winter semester (from November to December 2019) were randomly selected. The lottery method of creating a simple random sample of faculties was used. With the help of selected faculty teachers, there were identified 1,415 students. This procedure was chosen mainly due to the unavailability of the list of all students.

An email was sent to potential respondents with an invitation and instructions on how to complete the questionnaire. Respondents were also informed about the nature of the study and the intended use of the data. Four hundred and forty-seven questionnaires were returned with 412 being fully completed (effective response rate 29.11 percent). There were 53.4 percent $(\mathrm{N}=220)$ questionnaires completed by Czechs and 46.6 percent by Slovaks $(\mathrm{N}=192)$. As for the to gender, 42.96 percent of respondents $(\mathrm{N}=177)$ were men, and 57.04 percent $(\mathrm{N}=235)$ were women. For more extensive sample data, see Table 1.

Tab. 1 - The sample characteristics. Source: own research

\begin{tabular}{|l|l|l|l|l|}
\hline \multirow{2}{*}{ Variable } & \multicolumn{2}{|l|}{ CZ } & \multicolumn{2}{l|}{ SK } \\
\cline { 2 - 5 } & $\mathrm{N}$ & $\%$ of Total & $\mathrm{N}$ & $\%$ of Total \\
\hline GENX & 39 & $9.47 \%$ & 19 & $4.61 \%$ \\
\hline
\end{tabular}




\begin{tabular}{|l|l|l|l|l|}
\hline GENY & 60 & $14.56 \%$ & 57 & $13.83 \%$ \\
\hline GENZ & 121 & $29.37 \%$ & 116 & $28.16 \%$ \\
\hline Men & 87 & $21.12 \%$ & 90 & $21.84 \%$ \\
\hline Women & 133 & $32.28 \%$ & 102 & $24.76 \%$ \\
\hline Public universities & 141 & $34.23 \%$ & 104 & $25.24 \%$ \\
\hline Private universities & 79 & $19.17 \%$ & 88 & $21.36 \%$ \\
\hline Full-time students & 162 & $39.32 \%$ & 99 & $24.03 \%$ \\
\hline Part-time students & 58 & $14.08 \%$ & 93 & $22.57 \%$ \\
\hline
\end{tabular}

Based on the previous literature, the questionnaire consisted of 24 questions divided into four parts. The first part of the questionnaire measured employer attractiveness (EA) - 9 questions, second part informativeness and attractiveness of online job announcement - 8 questions, and third part the job pursuit intentions (JPI) - 3 questions. A seven-point Likert based scale was used to measure constructs in the first three parts of the questionnaire. The fourth part of the questionnaire included questions about nationality, gender, generation of the respondents, and the university status (public or private) - 4 questions. The questions are listed in the above section, for each variable separately.

The respondents' task was to select the exciting job announcement on the job listing sites (CR: https://www.jobs.cz/, SR: https://www.profesia.sk/) and to evaluate it based on the questions (indicators) presented in the questionnaire.

Before the administration of the survey, the questions were distributed to several doctoral students. Some revisions of translation to the Czech and Slovak languages were made based on their feedback.

\subsection{Analysis}

Multiple linear regression was used to determine which independent variables affect the response or help explain the response. Before the models were constructed, the multiple linear regression assumptions were checked. First, performed analyzes confirmed the linear relationship between the independent variable (JPI) and all offer dependent variables (EA, IER, ISB, ITO, ISE, IWA, IWLB, ICO, CA). Second, multivariate normality was checked, and it was found that errors between the observed and predicted values were normally distributed. Third, variance inflation factors (VIF) were computed to detect that there was no collinearity in the data (Table 3 and 4). Fourth, there was no clear pattern in the residuals' distribution; and thus, the homoscedasticity assumption was met. Fifth, the autocorrelation test was not performed because the data did not come from a time series.

Instead of fitting separate models for each predictor, the first model included all predictors, and the second model also second-degree predictors combinations. The least-squares approach was used to estimate the values of the model coefficients. All calculations were performed in SAS JMP version 15 . 


\section{RESULTS AND DISCUSSION}

\subsection{Descriptive statistics}

Table 2 illustrates the respondents' responses to the ten items studied in the instrument. Based on the mean scores, it can be identified that Job pursuit intentions (JPI) have the highest mean score (5.26). However, it should be noted that this value is mainly caused by the design of the study, as it is measured based on the most interesting job announcement. It is also important to point out that this is a dependent variable in our study. From independent variables, Content attractiveness (CA) has the highest mean score of 4.99, followed by Informativeness about employees' responsibilities (IER mean score $=4.24)$. The lowest score appeared to be for informativeness about training opportunities (ITO mean score $=2.95$ ), followed by Employer attractiveness (EA mean score $=3.00)$. The highest standard deviation had responses on Informativeness about the security of employment (ISE Std Dev = 1.45), followed by Informativeness about work-life balance $(I W L B$ Std Dev $=1.43)$. It indicates that the values are spread out over a broader range and thus signals a relatively large diversity of responses.

Tab. 3 - Responses to each measure. Source: own research

\begin{tabular}{|l|l|l|l|l|l|}
\hline Variable & Mean & Std Dev & \multicolumn{2}{|l|}{ Differences according to } \\
\hline Employer attractiveness (EA) & 3.00 & 0.96 & NS & NS & NS \\
\hline $\begin{array}{l}\text { Informativeness about employees' } \\
\text { responsibilities (IER) }\end{array}$ & 4.24 & 1.25 & NS & NS & NS \\
\hline $\begin{array}{l}\text { Informativeness about salary and } \\
\text { benefits (ISB) }\end{array}$ & 3.31 & 1.08 & NS & NS & NS \\
\hline $\begin{array}{l}\text { Informativeness about training op- } \\
\text { portunities (ITO) }\end{array}$ & 2.95 & 1.08 & NS & NS & NS \\
\hline $\begin{array}{l}\text { Informativeness about the security } \\
\text { of employment (ISE) }\end{array}$ & 4.22 & 1.45 & NS & NS & NS \\
\hline $\begin{array}{l}\text { Informativeness about working } \\
\text { atmosphere (IWA) }\end{array}$ & 3.94 & 1.39 & NS & NS & S \\
\hline $\begin{array}{l}\text { Informativeness about work-life } \\
\text { balance (IWLB) }\end{array}$ & 3.95 & 1.43 & S & NS & NS \\
\hline $\begin{array}{l}\text { Informativeness about career op- } \\
\text { portunities (ICO) }\end{array}$ & 3.25 & 1.16 & NS & NS & NS \\
\hline Content attractiveness (CA) & 4.99 & 1.20 & NS & NS & NS \\
\hline Job pursuit intentions (JPI) & 5.26 & 0.90 & NS & NS & NS \\
\hline
\end{tabular}

Note: $\mathrm{S}=$ significant, $\mathrm{NS}$ = non significant

Before the construction of the models themselves, differences as for the selected variables were also verified. The results show the only differences in Informativeness about working atmosphere (IWA) according to country ( $\mathrm{p}$-value 0.0389 ) and Informativeness about work-life balance (IWLB) according to gender ( $\mathrm{p}$-value 0.0444$)$ are significant. 


\subsection{Fitting multiple linear regression models}

To build the first model, we started with all predictors. The analysis showed that only Employer attractiveness (EA p-value < 0.0001), Informativeness about employees' responsibilities (IER $\mathrm{p}$-value $<0.0001$ ), Informativeness about salary and benefits (ISB p-value $<0.0001$ ) and Informativeness about work-life-balance (IWLB p-value $=0.0066)$ had a significant impact on Job pursuit intentions $(\mathrm{JPI})(\mathrm{R}$ Square $=0.34109742)$. Therefore, we continued without insignificant factors. As Table 3 presents, the proportion of the variance for a dependent variable that is explained by independent variables in a regression model is slightly higher ( $\mathrm{R}$ Square = 0.34590475). According to this model, the most important factor is Informativeness about salary and benefits (ISB coefficient estimation $=0.34027165$ ), the least important and even having a negative impact is Informativeness about employees' responsibilities (IER coefficient estimation $=-0.2126448)$.

Tab. 3 - The first model. Source: own research

\begin{tabular}{|c|c|c|c|c|c|}
\hline Term & ERC & Std Error & t Ratio & Prob $>|t|$ & VIF \\
\hline Intercept & 3.9359688 & 0.17661953 & 22.29 & $<0.0001$ & \\
\hline $\begin{array}{l}\text { Employer attrac- } \\
\text { tiveness (EA) }\end{array}$ & 0.27683424 & 0.04169537 & 6.64 & $<0.0001$ & 1.22274397 \\
\hline $\begin{array}{l}\text { Informativeness } \\
\text { about employees' } \\
\text { responsibilities } \\
\text { (IER) }\end{array}$ & -0.2126448 & 0.03078127 & -6.91 & $<0.0001$ & 1.13951818 \\
\hline $\begin{array}{l}\text { Informativeness } \\
\text { about salary and } \\
\text { benefits (ISB) }\end{array}$ & 0.34027165 & 0.03710804 & 9.17 & $<0.0001$ & 1.23880347 \\
\hline $\begin{array}{l}\text { Informativeness } \\
\text { about work-life } \\
\text { balance (IWLB) }\end{array}$ & 0.06876771 & 0.02602024 & 2.64 & 0.0085 & 1.0628723 \\
\hline RSquare & 0.34590475 & & & & \\
\hline RSquare Adjusted & 0.33126083 & & & & \\
\hline Source & DF & $\begin{array}{l}\text { Sum of } \\
\text { Squares }\end{array}$ & Mean Square & F Ratio & Prob $>$ F \\
\hline Model & 4 & 112.84929 & 28.2123 & 52.6734 & $<0.0001$ \\
\hline Error & 407 & 217.99253 & 0.5356 & & \\
\hline C. Total & 411 & 330.84182 & & & \\
\hline
\end{tabular}

Notes: ERC = Estimated Regression Coefficients, VIF $=$ Variance Inflation Factors, DF $=$ Degrees of Freedom, C. Total $=$ Corrected Total

The second model contained all predictors along with their second-degree interactions. The model was developed mainly because we doubted whether content attractiveness (CA) influences job pursuit intentions (JPI). After the initial deletion of factors that did not affect the job pursuit intentions $(\mathrm{JPI})(\mathrm{RSquare}=0.4023739546)$, we built the model presented in Table 4 . 
Tab. 4 - The second model. Source: own research

\begin{tabular}{|c|c|c|c|c|c|}
\hline Term & ERC & Std Error & t Ratio & Prob $>|t|$ & VIF \\
\hline Intercept & 3.96425993 & 0.17448791 & 22.72 & $<0.0001$ & \\
\hline $\begin{array}{l}\text { Informativeness about } \\
\text { salary and benefits (ISB) }\end{array}$ & 0.33850203 & 0.03662334 & 9.24 & $<0.0001$ & 1.23904604 \\
\hline $\begin{array}{l}\text { Employer attractiveness } \\
\text { (EA) }\end{array}$ & 0.27034249 & 0.04118964 & 6.56 & $<0.0001$ & 1.22529602 \\
\hline $\begin{array}{l}\text { Informativeness about } \\
\text { employees' responsibili- } \\
\text { ties (IER) }\end{array}$ & -0.2138802 & 0.03037834 & -7.04 & $<0.0001$ & 1.13967621 \\
\hline $\begin{array}{l}\text { Informativeness about } \\
\text { work-life balance (IWLB) }\end{array}$ & 0.06912523 & 0.02567806 & 2.69 & 0.0074 & 1.06288957 \\
\hline $\begin{array}{l}\text { (Employer attractiveness } \\
(\mathrm{EA})-2.99976)^{*}(\text { Content } \\
\text { attractiveness (CA)- } \\
4.98786)\end{array}$ & 0.11791658 & 0.03414485 & 3.45 & 0.0006 & 1.0038341 \\
\hline RSquare & 0.40237395 & & & & \\
\hline RSquare Adjusted & 0.40201715 & & & & \\
\hline Source & DF & $\begin{array}{l}\text { Sum of } \\
\text { Squares }\end{array}$ & $\begin{array}{l}\text { Mean } \\
\text { Square }\end{array}$ & F Ratio & Prob $>$ F \\
\hline Model & 5 & 119.07002 & 23.814 & 45.6552 & $<0.0001$ \\
\hline Error & 406 & 211.7718 & 0.5216 & & \\
\hline C. Total & 411 & 330.84182 & & & \\
\hline
\end{tabular}

Note: $\mathrm{ERC}=$ Estimated Regression Coefficients, VIF $=$ Variance Inflation Factors, DF $=$ Degrees of Freedom, C. Total $=$ Corrected Total

Both models support the hypotheses as follows: H1: Employer attractiveness (EA); H21: Informativeness about employee responsibilities (IER); H22: Informativeness about salary and benefits (ISB); and H26: Informativeness about work-life balance (IWLB). Otherwise, we were unable to confirm the contributions of variables H23: Training opportunities (ITO); H24: Security of employment (ISE); H25: Working atmosphere (IWA); H27: Career opportunities (ICO) and H3: Content attractiveness of the online announcement (CA).

The second model also confirmed that information about salary and benefits (ISB) is the salient factor that significantly affects job pursuit intentions (JPI). This result may be related to the fact that the Czech as well as the Slovak economy both continue to be centered on employees with low wages (Habánik et al., 2019). Moreover, the findings are consistent with previous results showing that more explicit wage and benefits information leads to higher job pursuit intentions (Verwaeren et al., 2017). Even though it goes beyond our research, we dare to say that information about salary and benefits (ISB) can also affect the perception of employer attractiveness (EA) in the Czech and Slovak labor market specifically.

The results regarding the work-life balance and employee responsibilities variables are also inter- 
esting, with IWLB proving the third most important in the first model and fourth in the second model, and IER the fourth most important in the first model and fifth in the second model. With regards to work-life balance (IWLB), the present data are consistent with Firfiray \& Mayo (2017), who found that Millennial and Gen X job seekers develop higher P-O fit perceptions for organizations, and thus assessed them as more attractive prospective employers. With these job seekers, supplement standard pay along with work-life balance in their recruitment materials compared more favorably with organizations than did supplement standard pay. Another interesting finding was that more specific information about employee responsibilities (IER) contributes to lower job pursuit intentions (JPI).

On the other hand, the second model did not affirm that the content attractiveness of the online announcement (CA) itself contributes to the job pursuit intentions (JPI). Still, it has been shown that this factor has indirect influence on actions taken in relation to employer attractiveness (EA). Concretely, more interesting the content is, the more attractive the employer is perceived. These additional findings are in line with Ganesan \& George (2019), who found that the aesthetic features of a print recruitment ad significantly enhanced the organizational attraction and attitudes, and thereby, job seekers' application intention. Nevertheless, this factor insignificantly induced job seeker intention to apply in an indirect way (Ganesan \& George, 2019).

\section{CONCLUSION}

Long term demographic trends have forced organizations to reconsider their attitudes regarding the labor market. It is not the potential candidates who compete for the job position, but that several organizations instead compete for the same employee in the labor market (Bejtkovský, 2018). In the never-ending war for talent, organizations must increase their recruitment efforts to be seen as the employer of choice by qualified applicants (Kumari \& Saini, 2018). Attracting and recruiting the right talent is a crucial differentiator in modern organizations (Shahbaz et al., 2019).

In today's digital age, many organizations use online recruitment to at least inform potential candidates about job opportunities or to enable them to apply for a job on the web (Mareschal \& Rudin, 2011). In light of a growing interest in the use of social media among HR activities, this study set out to answer the question of what factors affect job pursuit intentions (JPI) in the job listing websites environment.

The paper has drawn on the literature on job pursuit intentions (JPI) and employer attractiveness (EA) to study the phenomenon. Based on the published work, a nine-variables model was derived and tested using multiple linear regression. Two models were constructed: the first model contained all suspected variables (explaining the variance of 34.59 percent), while the second model contained their second-degree combinations (explaining the variance of 40.23 percent).

Both models found that: employer attractiveness (EA); informativeness about employee responsibilities (IER); informativeness about salary and benefits (ISB); and H26: informativeness about work-life balance (IWLB) all contribute to explaining the variance of the attractiveness of the employer (EA). Informativeness about salary and benefits (ISB) was the most crucial factor in both models. An interesting finding was that more specific information about employee responsibilities (IER) led to lower job pursuit intentions (JPI). We have also shown that the attractive- 
ness of the online announcement (CA) itself does not contribute to the job pursuit intentions (JPI). This factor acts only indirectly by acting on employer attractiveness (EA).

This study provides several implications for human resource management theory and practice. First, at the theoretical level, it extends the research to the factors affecting job pursuit intention (JPI) in the job listing websites environment. Second, for HR practitioners, it provides practical information about what the announcement of a job offer on job listing websites should contain in order to attract potential job seekers. However, it is also necessary to warn HR practitioners about trying to embellish the information provided, because job seekers now have access to many social media resources (e.g., independent web sites, chat rooms, and message boards) that provide additional information about potential employers (Djurdjevic et al., 2019). It is obvious that job applicants will compare these independent sources of information with the terms indicated by potential employers.

The current paper has several implications for theory and practice, although some limitations should be discussed. Data collected from university students might raise issues of generalizability to other populations. However, this demographic bias is not without justification, as young adults represent the largest group of social media users (Hoy \& Milne, 2010), which makes them the most effective group in determining online habits (Youssouf Osman \& Rahim, 2011). The fact that students are also future job candidates is also important. Obviously, for the above reasons students are often subjected to this type of research (Chang \& Tanford (2018); Chaudhary (2019); Firfiray \& Mayo (2017)). The responses to these types of questionnaires may be inaccurate due to a respondent's misunderstanding of a particular question or the effort by the respondent to be seen in the best possible light, even if the survey is anonymous (Rosenman et al., 2011).

Further research should primarily address the limitations of this work and therefore enhance this sample construction by the study of prospective employees beyond university graduates. Specifically, it could also focus on factors influencing the perception of employer attractiveness, such as an organization's prestige, i.e. it appears that organizations which feature information about their prestigious awards or labels (such as "Great place to work") are more attractive (Guillot-Soulez et al., 2019). Also, the personalization of the job announcements as a factor that attracts considerably more visual attention (Pfiffelmann et al., 2019) should also be addressed.

\section{References}

1. Aiman Smith, L., Bauer, T. N., \& Cable, D. M. (2001). Are you attracted? Do you intend to pursue? A recruiting policy-capturing study. Journal of Business and Psychology, 16 (2), 219-237. https://doi.org/10.1023/a:1011157116322

2. Allen, D. G., Mahto, R. V., \& Otondo, R. F. (2007). Web-based recruitment: Effects of information, organizational brand, and attitudes toward a Web site on applicant attraction. Journal of Applied Psychology, 92 (6), 1696-1708. https://doi.org/10.1037/0021-9010.92.6.1696

3. Al Marri, M. T. S. (2015). The Effectiveness Of Online Recruitment Advertisements And Recruitment Websites In Applicant Attraction. EPR A International Journal of Economic and Business Review, 3 (6), 15-22. 
4. Arijs, D., Botero, I. C., Michiels, A., \& Molly, V. (2018). Family business employer brand: Understanding applicants' perceptions and their job pursuit intentions with samples from the US and Belgium. Journal of Family Business Strategy, 9 (3), 180-191.

https://doi.org/10.1016/j.jfbs.2018.08.005

5. Barber, A. E. (1998). Recruiting Employees: Individual and Organizational Perspectives. SAGE Publications, Inc. https://doi.org/10.4135/9781452243351

6. Baum, M., \& Überschaer, A. (2018). When do employer awards pay off and when do they not? The impact of award familiarity on applicants' job pursuit intentions and the moderating role of corporate brand awareness. International Journal of Human Resource Management, 29 (21), 3093-3117. https://doi.org/10.1080/09585192.2016.1254101

7. Beenen, G., \& Pichler, S. (2014). Do I really want to work here? Testing a Model of Job Pursuit for MBA Interns. Resource Management, 53 (5), 661-682. https://doi.org/10.1002/hrm.21584

8. Bejtkovský, J. (2018). Factors influencing the job search and job selection in students of generation y in the Czech republic in the employer branding context. Management and Marketing, 13 (3), 1133-1149. https://doi.org/10.2478/MMCKS-2018-0028

9. Belinda, C. D., Westerman, J. W., \& Bergman, S. M. (2018). Recruiting with ethics in an online era: Integrating corporate social responsibility with social media to predict organizational attractiveness. Journal of Vocational Behavior, 109, 101-117. https://doi.org/10.1016/j.jvb.2018.10.001

10. Berthon, P., Ewing, M., \& Hah, L. L. (2005). Captivating company: dimensions of attractiveness in employer branding. International Journal of Advertising, 24 (2), 151-172. https://doi.org/10.1080/02650487.2005.11072912

11. Braddy, P. W., Meade, A. W., \& Kroustalis, C. M. (2006). Organizational recruitment website effects on viewers' perceptions of organizational culture. Journal of Business and Psychology, 20 (4), 525-543. https://doi.org/10.1007/s10869-005-9003-4

12. Breaugh, J. A. (2008). Employee recruitment: Current knowledge and important areas for future research. Human Resource Management Review, 18 (3), 103-118. https://doi.org/10.1016/j.hrmr.2008.07.003

13. Carpentier, M., Van Hoye, G., \& Weijters, B. (2019). Attracting applicants through the organization's social media page: Signaling employer brand personality. Journal of Vocational Behavior, 115. 103326. https://doi.org/10.1016/j.jvb.2019.103326

14. Catanzaro, D., Moore, H., \& Marshall, T. R. (2010). The Impact of Organizational Culture on Attraction and Recruitment of Job Applicants. Journal of Business and Psychology, 25 (4), 649-662. https://doi.org/10.1007/s10869-010-9179-0

15. Chang, W., \& Tanford, S. (2018). The Impact of Job Advertising on Hospitality Graduates' Job Pursuit Intention. Journal of Hospitality and Tourism Education, 30 (4), 215-228. https://doi.org/10.1080/10963758.2018.1480380

16. Chapman, D. S., Uggerslev, K. L., Carroll, S. A., Piasentin, K. A., \& Jones, D. A. (2005). Applicant attraction to organizations and job choice: A meta-analytic review of the correlates of recruiting outcomes. Journal of Applied Psychology, 90 (5), 928-944. https://doi.org/10.1037/0021-9010.90.5.928 
17. Chaudhary, R. (2019). Green human resource management and job pursuit intention: Examining the underlying processes. Corporate Social Responsibility and Environmental Management, 26 (4), 929-937. https://doi.org/10.1002/csr.1732

18. Chitu, M. G., Zagan, R., Firsa, I., Gherasim, A. M., \& Manea, E. (2014). Factors Influencing The Choice Of Profession and Employment - Case Study. L. G. Chova, A. L. Martinez, \& I. C. Torres (Eds.), Edulearn14: 6th International Conference on Education and New Learning Technologies.

19. De Cooman, R., \& Pepermans, R. (2012). Portraying fitting values in job advertisements. Personnel Review, 41 (2), 216-232. https://doi.org/10.1108/00483481211200042

20. Djurdjevic, E., Rosen, C. C., Conroy, S. A., Rawski, S. L., \& Sosna, K. U. (2019). The influence of political climate on job pursuit intentions and the moderating effect of Machiavellianism. International Journal of Selection and Assessment, 27 (2), 180-192. https://doi.org/10.1111/ijsa.12242

21. Dvorsky, J., Belas, J., Gavurova, B., \& Brabenec, T. (2020). Business risk management in the context of small and medium-sized enterprises. Economic Research-Ekonomska Istraživanja, 33(1), 1-19. https://doi.org/10.1080/1331677X.2020.1844588

22. Firfiray, S., \& Mayo, M. (2017). The Lure of Work-Life Benefits: Perceived PersonOrganization Fit As A Mechanism Explaining Job Seeker Attraction To Organizations. Human Resource Management, 56 (4), 629-649. https://doi.org/10.1002/hrm.21790

23. Ganesan, M., \& George, E. P. (2019). A study on the effectiveness of aesthetically appealing print recruitment advertisement. Management Research Review, 42(4), 506-520. https://doi.org/10.1108/MRR-01-2018-0023

24. Gavurova, B., Packova, M., Misankova, M., \& Smrcka, L. (2017). Predictive potential and risks of selected bankruptcy prediction models in the Slovak business environment. Journal of Business Economics and Management, 18(6), 1156-1173. https://doi.org/10.3846/16111699.2017.1400461

25. Ghielen, S. T. S., Cooman, R. D. E., \& Sels, L. (2018). Refining employer branding research: Linking employer attractiveness to clear and targeted employer brands. Paper presented at the 78th Annual Meeting of the Academy of Management, AOM 2018.

26. Gregorka, L., Silva, S., \& Silva, C. (2020). Employer branding practices amongst the most attractive employers of IT and engineering sector. International Journal of Human Capital and Information Technology Professionals, 11 (1), 1-16. https://doi.org/10.4018/IJHCITP.2020010101

27. Guillot-Soulez, C., Saint-Onge, S., \& Soulez, S. (2019). Linking employer labels in recruitment advertising, governance mode and organizational attractiveness. Recherche et Applications en Marketing, 34 (3), 5-26. https://doi.org/10.1177/2051570719843066

28. Habánik, J., Grenčíková, A., \& Krajčo, K. (2019). New technology impact on the Sustainable Development. Engineering Economics, 30 (1), 41-49. https://doi.org/10.5755/j01.ee.30.1.20776

29. Highhouse, S., Lievens, F., \& Sinar, E. F. (2003). Measuring Attraction to Organizations. Educational and Psychological Measurement, 63 (6), 986-1001. https://doi.org/10.1177/0013164403258403 
30. Hinojosa, A. S., Walker, H. J., \& Payne, G. T. (2015). Prerecruitment organizational perceptions and recruitment website information processing. International Journal of Human Resource Management, 26 (20), 2617-2631. https://doi.org/10.1080/09585192.2014.1003081

31. Hoy, M. G., \& Milne, G. (2010). Gender Differences in Privacy-Related Measures for Young Adult Facebook Users. Journal of Interactive Advertising, 10 (2), 28-45.

https://doi.org/10.1080/15252019.2010.10722168

32. Jiang, T., Lu, L., \& Iles, P. (2011). Employer-brand equity, organizational attractiveness and talent management in the Zhejiang private sector, China. Journal of Technology Management in China, 6 (1), 97-110. https://doi.org/10.1108/17468771111105686

33. Kissel, P., \& Buttgen, M. (2015). Using social media to communicate employer brand identity: The impact on corporate image and employer attractiveness. Journal of Brand Management, 22 (9), 755-777. https://doi.org/10.1057/bm.2015.42

34. Koisova, E., Habanik, J., Virglerova, Z., \& Rozsa, Z. (2017). SMEs Financing as an Important Factor of Business Environment in Slovak Republic Regions. Montenegrin Journal of Economics, 13 (2), 129-140. https://doi.org/10.14254/1800-5845/2017.13-2.8

35. Kumari, S., \& Saini, G. K. (2018). Do instrumental and symbolic factors interact in influencing employer attractiveness and job pursuit intention? Career Development International, 23 (4), 444-462. https://doi.org/10.1108/cdi-03-2018-0069

36. Macan, T. H., Avedon, M. J., Paese, M., \& Smith, D. E. (1994). The effects of job applicants' reactions to Cognitive Ability Tests and an Assessment Center. Personnel Psychology, 47 (4), 715-738. https://doi.org/10.1111/j.1744-6570.1994.tb01573.x

37. Madera, J. M. (2012). Using social networking websites as a selection tool: The role of selection process fairness and job pursuit intentions. International Journal of Hospitality Management, 31 (4), 1276-1282. https://doi.org/10.1016/j.ijhm.2012.03.008

38. Mareschal, P. M., \& Rudin, J. P. (2011). E-government versus e-business: A comparison of online recruitment in the public and private sectors. American Review of Public Administration, 41 (4), 453-467. https://doi.org/10.1177/0275074010375573

39. Maurer, S. D., \& Liu, Y. (2007). Developing effective e-recruiting websites: Insights for managers from marketers. Business Horizons, 50 (4), 305-314. https://doi.org/10.1016/j.bushor.2007.01.002

40. Malega, P., Rudy, V., Kovac, J., \& Kovac, J. (2019). The Competitive Market Map as the Basis for an Evaluation of the Competitiveness of the Slovak Republic on an International Scale. Journal of Competitiveness, 11 (4), 103-119. https://doi.org/10.7441/joc.2019.04.07

41. Mura, L. (2019). Entrepreneurship internationalization - Case of Slovak family businesses. $A d$ Alta-Journal of Interdisciplinary Research, 9 (1), 222-226.

42. Neubert, M. J., \& Wood, M. S. (2019). Espoused Religious Values in Organizations and Their Associations with Applicant Intentions to Pursue a Job. Journal of Business and Psychology, 34 (6), 803-823. https://doi.org/10.1007/s10869-018-9594-1

43. Oikarinen, E. L., \& Söderlund, M. (2016). The effects of humour in online recruitment advertising. Australasian Marketing Journal, 24 (3), 180-186.

https://doi.org/10.1016/j.ausmj.2016.02.005 
44. Peiffer, M., Habibpour, M. M., Jegers, M., \& Pepermans, R. (2018). The importance of sectorstereotypical images in relation to job pursuit intentions. Nonprofit Management \& Leadership, 28 (4), 553-564. https://doi.org/10.1002/nml.21304

45. Pfiffelmann, J., Dens, N., \& Soulez, S. (2019). Personalized advertisements with integration of names and photographs: An eye-tracking experiment. Journal of Business Research. https://doi.org/10.1016/j.jbusres.2019.08.017

46. Priyadarshini, C., Sreejesh, S., \& Jha, R. R. (2019). Impact of informational characteristics of the recruitment website on graduating students' job pursuit intention: A moderated mediation study. International Journal of Human Capital and Information Technology Professionals, 10 (2), 1-19. https://doi.org/10.4018/IJHCITP.2019040101

47. Rosenman, R., Tennekoon, V., \& Hill, L. G. (2011). Measuring bias in self-reported data. International Journal of Behavioural and Healthcare Research, 2 (4), 320-332. https://doi.org/10.1504/IJBHR.2011.043414

48. Rynes, S., Bretz, B., \& Gerhart, B. (1991). The importance of recruitment in job choice: A different way of looking. Personnel Psychology, 44, 487-521.

49. Sander, T., \& Teh, P. L. (2019). My Employer's Prestige, My Prestige. In: Rocha Á., Adeli, H., Reis, L. Costanzo, S. (Eds.), Advances in Intelligent Systems and Computing. Springer, Cham.

50. Shahbaz, U., Beheshti, A., Nobari, S., Qu, Q., Paik, H. Y., \& Mahdavi, M. (2019) iRecruit: Towards Automating the Recruitment Process. In: Ho-Pun, L., Sajib, M. (Eds.), Lecture Notes in Business Information Processing, 139-152. Springer Nature.

51. Stachová, K., Papula, J., Stacho, Z., \& Kohnová, L. (2019). External Partnerships in Employee Education and Development as the Key to Facing Industry 4.0 Challenges. Sustainability, 11 (2), 345-364. https://doi.org/10.3390/su11020345

52. Thompson, L. F., Braddy, P. W., \& Wuensch, K. L. (2008). E-recruitment and the benefits of organizational web appeal. Computers in Human Behavior, 24 (5), 2384-2398.

https://doi.org/10.1016/j.chb.2008.02.014

53. Tsai, Y. H., Joe, S. W., Lin, C. P., \& Wang, R. T. (2014). Modeling Job Pursuit Intention: Moderating Mechanisms of Socio-Environmental Consciousness. Journal of Business Ethics, 125 (2), 287-298. https://doi.org/10.1007/s10551-013-1919-4

54. Tsai, Y. H., Lin, C. P., Ma, H. C., \& Wang, R. T. (2015). Modeling corporate social performance and job pursuit intention: Forecasting the job change of professionals in technology industry. Technological Forecasting and Social Change, 99, 14-21.

https://doi.org/10.1016/j.techfore.2015.06.026

55. Verwaeren, B., Van Hoye, G., \& Baeten, X. (2017). Getting bang for your buck: the specificity of compensation and benefits information in job advertisements. International Journal of Human Resource Management, 28 (19), 2811-2830. https://doi.org/10.1080/09585192.2016.1138989

56. Wang, R. T. (2013). Modeling Corporate Social Performance and Job Pursuit Intention: Mediating Mechanisms of Corporate Reputation and Job Advancement Prospects. Journal of Business Ethics, 117 (3), 569-582. https://doi.org/10.1007/s10551-012-1538-5 
57. Word, J., \& Park, S. M. (2015). The new public service? Empirical research on job choice motivation in the nonprofit sector. Personnel Review, 44 (1), 91-118.

https://doi.org/10.1108/pr-07-2012-0120

58. Yang, S., Khochuaklang, S., \& Stargell, P. (2020). Work-life balance dilemma of Chinese millennial employees: Factors affecting the perception of work-life balance. Test Engineering and Management, 83, 3008-3024.

59. Youssouf Osman, F., \& Rahim, N. Z. A. (2011). Self-disclosure and Social network sites users' awareness.Paper presented at the 2011 International Conference on Research and Innovation in Information Systems.

\section{Contact information}

Assoc. prof. Zoltan Rozsa, PhD.

Alexander Dubček University of Trenčin

Faculty of Social and Economic Relations

Slovakia

E-mail: zoltan.rozsa@tnuni.sk.

ORCID: 0000-0002-5748-5702

Ing. Veronika Machova, MBA

Faculty of Business Administration

University of Economics

Nám. W. Churchila 1938/4

13067 Prague

Czech Republic

E-mail:macv11@vse.cr.

ORCID: 0000-0001-5479-6655 